JOSETA: Journal of Socio Economic on Tropical Agriculture

Volume 1 Nomor 3: 1-8 Desember (2019)

JOSETA: Journal of Socio Economic on Tropical Agriculture http://joseta.faperta.unand.ac.id

ISSN : 2686 - 0953 (Online)

\title{
ANALISIS AKUNTABILITAS PENGELOLAAN KEUANGAN NAGARI DI KECAMATAN KOTO XI TARUSAN KABUPATEN PESISIR SELATAN
}

\author{
ANALYSIS MANAGEMENT ACCOUNTABILITY OF VILLAGE FINANCIAL IN KOTO XI \\ TARUSAN DISTRICT PESISIR SELATAN REGENCY
}

\author{
Ninda Fatmawati ${ }^{1}$, Rudi Febriamansyah ${ }^{2}$, Rafnel Azhari ${ }^{3}$ \\ ${ }^{1}$ Mahasiswa Program Studi Agribisnis, Fakultas Pertanian, Universitas Andalas, Padang \\ 2Prodi Agribisnis, Faperta Unand, Padang \\ ${ }^{3}$ Agribisnis, Faperta Unand, Padang \\ Received: $15^{\text {th }}$ Oktober, 2019; $1^{\text {st }}$ Revision: $12^{\text {th }}$ Novermber, 2019; Accepted: $20^{\text {th }}$ Desember, 2019
}

\begin{abstract}
Abstrak
Penelitian ini merupakan penelitian deskriptif kuantitatif yang bertujuan untuk menganalisis akuntabilitas pengelolaan keuangan nagari dengan membandingkan pelaksanaan pengelolaan keuangan nagari di Kecamatan Koto XI Tarusan dengan Permendagri Nomor 113 Tahun 2014 tentang Pengelolaan Keuangan Desa. Metode pengumpulan data yang digunakan dalam penelitian ini adalah wawancara terstruktur dengan responden penelitian. Hasil penelitian menunjukan bahwa akuntabilitas pada aspek perencanaan adalah $48 \%$, akuntabilitas pada aspek pelaksanaan adalah $87 \%$, akuntabilitas pada aspek penatausahaan adalah $33 \%$, akuntabilitas pada aspek pelaporan adalah 59\%, dan akuntabilitas pada aspek pertanggungjawaban adalah $68 \%$. Secara keseluruhan akuntabilitas pengelolaan keuangan nagari di Kecamatan Koto XI Tarusan sudah akuntabel. Hanya terdapat 3 dari 23 nagari yang tidak akuntabel.
\end{abstract}

Kata Kunci: akuntabilitas pengelolaan keuangan, Permendagri No. 113 Tahun 2014

\section{Abstract}

This research is a descriptive quantitative research which aims to determine the accountability management of village financial by comparing the implementation of village financial in the Koto XI Tarusan District with Permendagri No. 113 Year 2014 about Village Financial Management Guideline. The data collection method used in this research was structured interviews with research respondance. The results showed that the accountability in the planning aspect is 48\%, accountability on aspect of implementation is $87 \%$, accountability in the administration aspect is 33\%, accountability in the reporting aspect is 59\%, and the last accountability is 68\% . Over all accountability management of village financial in Koto XI Tarusan District is accountable. Just 3 of the 23 nagari in Koto XI Tarusan district was not accountable.

Keywords: village financial management accountability, Pemendagri No. 113 Year 2014 


\section{PENDAHULUAN}

Pengertian desa menurut Undang-Undang nomor 6 tahun 2014 adalah kesatuan masyarakat hukum yang memiliki batas wilayah yang berwenang untuk mengatur dan mengurus urusan pemerintahan, kepentingan masyarakat setempat berdasarkan prakarsa masyarakat, hak asal usul, dan/ atau hak tradisional yang diakui dan dihormati dalam sistem pemerintahan Negara Kesatuan Republik Indonesia. Keuangan desa menurut pasal 71 UU No.6 Tahun 2014 adalah semua hak dan kewajiban desa yang dapat dinilai dengan uang, serta segala sesuatu berupa uang dan barang yang berhubungan dengan pelaksanaan hak dan kewajiban. Hak dan kewajiban dapat menimbulkan pendapatan, belanja, pembiayaan, dan pengelolaan keuangan desa. Sedangkan keuangan desa menurut Permendagri Nomor 113 tahun 2014 adalah keseluruhan kegiatan yang meliputi perencanaan, pelaksanaan, penatausahaan, pelaporan dan pertanggungjawaban keuangan desa.

Berdasarkan pengertian tersebut dapat dilihat bahwa pengelolaan keuangan desa merupakan tindakan yang meliputi perencanaan, pelaksanaan, penatausahaan, pelaporan dan pertanggungjawaban. Pertanggungjawaban pengelolaan keuangan desa oleh pemerintah desa disebut juga dengan istilah akuntabilitas. Pentingnya akuntabilitas dalam pengelolaan keuangan desa ini karena akuntabilitas menjamin nilai-nilai seperti efisiensitas, efektivitas, realibilitas dan prediktibilitas. Suatu akuntabilitas tidak abstrak tapi konkrit dan harus ditentukan oleh hukum melalui seperangkat prosedur yang sangat spesifik mengenai masalah apa saja yang harus dipertanggungjawabkan. Dalam pelaksanaan akuntabilitas di lingkungan pemerintahan dapat diperhatikan prinsip-prinsip akuntabilitas sebagai berikut: (1) harus ada komitmen dari pimpinan dan staf instansi untuk melaksanakan pengelolaan pelaksanaan misi agar akuntabel; (2) harus merupakan suatu system yang dapat menjamin penggunaan sumber daya secara konsisten dengan peraturan perundang-undangan yang berlaku; (3) harus dapat menunjukan tingkat pencapaian tujuan dan sasaran yang telah ditetapkan; (4) harus berorientasi pada pencapaian visi dan misi serta hasil dan manfaat; (5) harus jujur, objektif, transparan, dan inovatif sebagai katalisator perubahan (Nafidah, 2017:27)

Kabupaten Pesisir Selatan merupakan salah satu kabupaten yang berada di Provinsi Sumatera Barat yang wilayahnya membentang di sepanjang garis pantai Pulau Sumatera. Di Kabupaten ini, desa lebih dikenal dengan sebutan Nagari. Kabupaten ini memiliki 15 kecamatan yang terdiri atas 182 nagari. Kecamatan yang memiliki APB Nagari tertinggi di Kabupaten ini adalah Kecamatan Koto XI Tarusan yakni Anggaran Pendapatan sebesar Rp32.817.641.987 dan Anggaran Belanja Nagari sebesar Rp33.081.378.290 pada tahun 2018.

Penggunaan belanja nagari berdasarkan APB Nagari dalam pasal 100 PP Nomor 47 Tahun 2015 digunakan dengan ketentuan: (1) paling sedikit $70 \%$ ( $\geq 70 \%)$ dari jumlah anggaran belanja nagari digunakan untuk mendanai penyelenggaraan pemerintah nagari, pelaksanaan pembangunan nagari, pembinaan kemasyarakatan, dan pemberdayaan masyarakat nagari; (2) paling banyak 30\% $(\leq 30 \%)$ dari jumlah anggaran belanja nagari digunakan untuk penghasilan tetap dan tunjangan wali nagari dan perangkat nagari, operasional pemerintah nagari, tunjangan dan opersional Bamus, serta insentif RT dan RW. Berdasarkan peraturan tersebut penggunaan belanja nagari untuk pengahasilan tetap, operasional pemerintah nagari dan tunjangan dan operasional Bamus menggunakan sumber dana dari Alokasi Dana Desa. Sedangkan untuk 4 (empat) bidang lainnya mengunakan sumber Dana Desa. Namun berdasarkan hasil survei di Kecamatan Koto XI Tarusan, penggunaan sumber dana Alokasi Dana Desa tidak hanya digunakan untuk membiayai penghasilan tetap dan operasioanal pemerintah nagari saja, namun juga digunakan untuk bidang pemberdayaan dan bidang pembinaan masyarakat nagari. Sedangkan sumber Dana Desa diprioritaskan pada 
bidang pelaksanaan pembangunan nagari. Oleh karena itu peneliti merasa perlu mengadakan penelitian terkait akuntabilitas pengelolaan keuangan nagari di Kecamatan Koto XI Tarusan.

\section{METODE PENELITIAN}

Penelitian ini dilaksanakan di 23 nagari yang terdapat di Kecamatan Koto XI Tarusan. Data yang digunakan adalah data primer dan data sekunder. Data primer didapatkan dari wawancara terstruktur dengan responden penelitian sedangkan data sekunder di dapatkan dari Badan Pengelolaan Keuangan Daerah (BPKD) Kabupaten Pesisir Selatan dan BPS Kabupaten Pesisir Selatan. Jumlah responden dalam penelitian ini berjumlah 33 orang yang terdiri atas perangkat nagari yang mengetahui tentang pengelolaan keuangan nagari. Alat yang digunakan untuk mengumpulkan data dalah kuesioner. Analisis data menggunakan skala Guttman yaitu "ya-tidak" dan kemudian berdasarkan jawaban dari kuesioner akan dipersentasekan.. "Ya" berarti pengelolaan keuangan nagari telah sesuai dengan Permendagri, sedangkan "Tidak" berarti bahwa pengelolaan keuangan nagari tidak sesuai dengan Permendagri.

Cara menghitung akuntabilitas setiap aspek pengelolaan keuangan nagari adalah :

$$
\% \text { akuntabilitas }=\frac{\text { Jumlah nagari yang menjawab"Ya" }}{\text { Jumlah Total Nagari }} \times 100 \%
$$

Cara menghitung akuntabilitas setiap nagari dalam pengelolaan keuangan nagari adalah:

$$
\% \text { akuntabilitas }=\frac{\text { Jumlah jawaban kuesioner } " Y a "}{\text { Jumlah Total Kuesioner }} \times 100 \%
$$

Berdasarkan rumus tersebut, maka untuk menentukan ukuran akuntabilitas pengelolaan keuangan nagari maka digunakan rumus sebagai berikut:

$$
\begin{aligned}
& \operatorname{Interval}(\mathrm{I}) \quad=\text { Range }(\mathrm{R}) / \operatorname{Kategori}(\mathrm{K}) \\
& =100 / 2 \\
& =50
\end{aligned}
$$

Jadi, batas Inteval (I) adalah 50\% sehingga kategori dalam analisis ini adalah akuntabel dan tidak akuntabel. Pengelolaan dikatakan akuntabel jika persentase $>50 \%$, sedangkan pengelolaan keuangan nagari dikatakan tidak akuntabel jika persentase $\leq 50 \%$.

\section{HASIL DAN PEMBAHASAN}

\section{Akuntabilitas Pengelolaan Keuangan Nagari di Kecamatan Koto XI Tarusan}

Akuntabilitas pengelolaan keuangan nagari merupakan kesesuaian pengelolaan keuangan nagari di Kecamatan Koto XI Tarusan dengan Peraturan Menteri Dalam Negeri (Permendagri) Nomor 113 Tahun 2014 tentang Pengelolaan Keuangan Desa. Hasil dari kelima aspek tersebut dapat dilihat pada tabel berikut: 
Tabel 1. Akuntabilitas Aspek Perencanaan dalam Pengelolaan Keuangan Nagari di Kecamatan Koto XI Tarusan

\begin{tabular}{llc}
\hline \multicolumn{1}{c}{ Aspek Perencanaan } & $\begin{array}{c}\text { Jumlah Nagari } \\
\text { yang } \\
\text { Menjawab } \\
\text { "Ya" }\end{array}$ & $\begin{array}{c}\text { Jumlah } \\
\text { Total } \\
\text { Nagari }\end{array}$ \\
\hline $\begin{array}{l}\text { 1. Sekretaris Nagari menyusun Rancangan Peraturan Nagari tentang APB } \\
\text { Nagari berdasarkan RKP Nagari tahun berkenan. }\end{array}$ & 13 \\
\hline $\begin{array}{l}\text { Sekretaris Nagari menyampaiakan rancangan Peraturan nagari tentang APN } \\
\text { nagari kepada Wali Nagari }\end{array}$ & 14 & 23 \\
\hline $\begin{array}{l}\text { Rancangan peraturan nagari tentang APB nagari disampaikan oleh Wali } \\
\text { Nagari kepada Bamus untuk disepakati bersama } \\
\text { lambat bulan Oktober tahun berjalan }\end{array}$ & 14 \\
\hline $\begin{array}{l}\text { Rancangan peraturan nagari tentang APB nagari yang telah disepakati } \\
\text { bersama disampaikan oleh Wali Nagari kepada Bupati melalui Camat paling } \\
\text { lambat 3 (tiga) hari sejak disepakati }\end{array}$ & 13 \\
\hline \multicolumn{1}{c}{ Jumlah Akuntabilitas } & 1 \\
\hline
\end{tabular}

Berdasarkan tabel di atas dapat dilihat bahwa akuntabilitas aspek perencanaan adalah $48 \%$. Butir perencanaan yang paling banyak tidak terlaksana sesuai dengan peraturan terletak pada butir ke-5, yakni tentang waktu penyampaian rancangan peraturan nagari tentang APB nagari oleh Wali Nagari kepada Bupati. Di dalam peraturan dikatakan waktu penyampaian paling lambat selama 3 (tiga) hari, namun dalam pelaksanaannya membutuhkan waktu dari 7 hingga 14 hari. Waktu yang dibutuhkan lebih lama dibandingkan dengan yang tercantum dalam peraturan karena proses di Kecamatan yang cukup lama.

Tabel 2. Akuntabilitas Aspek Pelaksanaan dalam Pengelolaan Keuangan Nagari di Kecamatan Koto XI Tarusan

\begin{tabular}{|c|c|c|}
\hline Aspek Pelaksanaan & $\begin{array}{c}\text { Jumlah Nagari } \\
\text { yang Menjawab } \\
\text { "Ya" }\end{array}$ & $\begin{array}{c}\text { Jumlah } \\
\text { Total } \\
\text { Nagari }\end{array}$ \\
\hline $\begin{array}{l}\text { 1. Semua penerimaan dan pengeluaran nagari yang masih mencakup dalam } \\
\text { kewenangan nagari dilaksanakan melalui rekening kas nagari }\end{array}$ & 23 & 23 \\
\hline 2. Semua penerimaan dan pengeluaran nagari wajib didukung oleh bukti yang sah & 23 & 23 \\
\hline $\begin{array}{l}\text { 3. Penggunaan biaya tak terduga terlebih dahulu harus dibuat Rincian Anggaran } \\
\text { Biaya yang telah disahkan oleh Wali Nagari }\end{array}$ & 7 & 23 \\
\hline $\begin{array}{l}\text { 4. Pelaksanaan kegiatan mengajukan pendanaan untuk melaksanakan kegiatan } \\
\text { harus disertai dengan dokumen antara lain Rencana Anggaran Biaya }\end{array}$ & 23 & 23 \\
\hline $\begin{array}{l}\text { 5. Rencana Anggaran Biaya diverifikasi oleh Sekretaris Nagari dan disahkan oleh } \\
\text { Wali Nagari }\end{array}$ & 16 & 23 \\
\hline $\begin{array}{l}\text { 6. Berdasarkan RAB, pelaksanaan kegiatan mengajukan Surat Permintaan } \\
\text { Pembayaran (SPP) kepada Wali Nagari }\end{array}$ & 21 & 23 \\
\hline $\begin{array}{l}\text { 7. Surat Permintaan Pembayaran (SPP) tidak boleh dilakukan sebelum barang dan } \\
\text { atau jasa diterima }\end{array}$ & 23 & 23 \\
\hline $\begin{array}{l}\text { 8. SPP diverifikasi oleh Sekretaris Nagari, lalu disetujui oleh Wali Nagari, } \\
\text { kemudian Bendahara melakukan pembayaran }\end{array}$ & 21 & 23 \\
\hline $\begin{array}{l}\text { 9. Bendahara harus melakukan pencatatan pengeluran setelah pembayaran } \\
\text { dilakukan }\end{array}$ & 23 & 23 \\
\hline Jumlah & 180 & 207 \\
\hline \% Akuntabilitas & \multicolumn{2}{|c|}{$87 \%$} \\
\hline
\end{tabular}


Berdasarkan tabel tersebut dapat dilihat bahwa akuntabilitas aspek pelaksanaan adalah 87\%. Secara keseluruhan aspek pelaksanaan telah dijalankan dengan baik di setiap nagari. Butir aspek pelaksanaan terendah yakni mengenai pembuatan rincian anggaran biaya untuk penggunaan biaya tak terduga. Hanya ada 7 nagari dari 23 nagari yang melaksanakan ini. Alasan nagari tidak melaksanakan butir ini karena memang untuk tahun anggaran 2018 tidak dibuatkan rinciannya. Selain itu alasan yang dikemukakan adalah karena telah adanya SPP sehingga rincian anggran biaya tidak diperlukan lagi.

Tabel 3. Akuntabilitas Aspek Penatausahaan Pengelolaan Keuangan Nagri di Kecamatan Koto XI Tarusan

\begin{tabular}{lcc}
\hline \multicolumn{1}{c}{ Aspek Penatausahaan } & $\begin{array}{c}\text { Jumlah Nagari } \\
\text { yang Menjawab } \\
\text { "Ya" }\end{array}$ & $\begin{array}{c}\text { Jumlah } \\
\text { Total } \\
\text { Nagari }\end{array}$ \\
\hline $\begin{array}{l}\text { 1. Bendahara Nagari wajib melakukan pencatatan setiap penerimaan dan } \\
\text { pengeluaran serta melakukan tutup buku setiap akhir bulan secara tertib }\end{array}$ & 7 & 23 \\
\hline $\begin{array}{l}\text { 2. Bendahara wajib mempertanggungjawabkan uang melalui laporan } \\
\text { pertanggungjawaban }\end{array}$ & 8 & 23 \\
\hline $\begin{array}{l}\text { 3. Laporan pertanggungjawaban disampaikan setiap bulan kepada Wali } \\
\text { Nagari dan paling lambat tanggal 10 bulan berikutnya } \\
\text { Jumlah }\end{array}$ & 8 & 23 \\
\hline \% Akuntabilitas & 23 & 69 \\
\hline
\end{tabular}

Berdasarkan tabel di atas dapat disimpulkan bahwa aspek penatausahaan merupakan aspek dengan persentase terendah dibandingkan dengan aspek yang lainnya. Meskipun hanya terdiri atas 3 butir saja namun kebanyakan nagari di Kecamatan Koto XI Tarusan tidak dapat melaksanakan sepenuhnya. Hal ini dikarenakan bahwa tutup buku tidak dilakukan setiap bulannya melainkan hanya 2 kali dalam setahu. Selain itu yang mempertanggungjawabkan uang melalui laporan keuangan bukanlah bendahara melainkan PTPKN, LKPJ, dan bahkan Sekretaris Nagari. Selanjutnya waktu yang diperlukan dalam penyampaian laporan pertanggungjawaban kepada Wali Nagari membutuhkan waktu hingga 2 minggu.

Tabel 4. Akuntabilitas Aspek Pelaporan dalam Pengelolaan Keuangan Nagari di Kecamatan Koto XI Tarusan

\section{Aspek Pelaporan}

\begin{tabular}{cc}
$\begin{array}{c}\text { Jumlah Nagari } \\
\text { yang Menjawab } \\
\text { "Ya" }\end{array}$ & $\begin{array}{c}\text { Jumlah } \\
\text { Total } \\
\text { Nagari }\end{array}$ \\
\hline 12 & 23 \\
15 & 23 \\
& \\
\hline 27 & 46 \\
\hline
\end{tabular}

Aspek pelaporan hanya terdiri atas 2 (dua) butir pernyataan dengan perolehan persentase adalah 59\%. Hal ini berarti bahwa aspek pelaporan sudah akuntabel. Hal yang menjadi masalah utama dalam aspek pelaporan ini adalah waktu penyampaian laporan yang tidak sesuai dengan 
seharusnya serta perangkat nagari yang menyusun laporan itu sendiri. Hampir setangah nagari tidak melaksanakan sesuai dengan peraturan karena perangkat nagari yang menyusun laporan itu bukanlah sekretaris, melainkan bendahara bahkwa PTPKN. sedangkan untuk waktunya lebih lama dibandingkan yang seharusnya.

Tabel 5. Akuntabilitas Aspek Pertanggungjawaban dalam Pengelolaan Keuangan Nagari di Kecamatan Koto XI Tarusan

\begin{tabular}{|c|c|c|}
\hline Aspek Pertanggungjawaban & $\begin{array}{l}\text { Jumlah Nagari } \\
\text { yang Menjawab } \\
\text { "Ya" }\end{array}$ & $\begin{array}{l}\text { Jumlah } \\
\text { Total } \\
\text { Nagari }\end{array}$ \\
\hline $\begin{array}{l}\text { 1. Wali Nagari mempunyai kewajiban untuk menyampaikan laporan } \\
\text { pertanggungjawaban atas realisasi pelaksanaan APB nagari kepada } \\
\text { Bupati di akhir tahun anggran }\end{array}$ & 6 & 23 \\
\hline $\begin{array}{l}\text { 2. Laporan pertanggungjawaban realisasi pelaksanaan APB nagari terdiri } \\
\text { atas pendapatan, belanja, dan pembiayaan }\end{array}$ & 20 & 23 \\
\hline $\begin{array}{l}\text { 3. Laporan pertanggungjawaban realisasi pelaksanaan APB nagari } \\
\text { ditetapkan dengan Peraturan nagari }\end{array}$ & 12 & 23 \\
\hline $\begin{array}{l}\text { 4. Peraturan nagari tentang laporan pertanggungjawaban dilampiri dengan } \\
\text { format pertanggungjawbaan realisasi pelaksanaan APB nagari tahun } \\
\text { anggran berkenan, format laporan kekayaan milik nagari per-31 } \\
\text { Desember tahun anggrann berkenan, dan format laporan program } \\
\text { pemerintah dan pemerintah daerah yang masuk ke nagari }\end{array}$ & 19 & 23 \\
\hline $\begin{array}{l}\text { 5. Laporan realisasi dan laporan pertanggungjawaban realisasi } \\
\text { pelaksanaan APB nagari diinformasikan kepada masyarakat secara } \\
\text { tertulis dan media informasi yang udah diakses oleh masyarakat }\end{array}$ & 17 & 23 \\
\hline $\begin{array}{l}\text { 6. Laporan realisasi dan laporan pertanggungjawaban realisasi } \\
\text { pelaksanaan APB nagari disampaiakan kepada Bupati paling lambat } 1 \\
\text { ( satu) bulan setelah akhir tahun anggaran berkenan }\end{array}$ & 20 & 23 \\
\hline Jumlah & 94 & 138 \\
\hline \% Akuntabilitas & $68 \%$ & \\
\hline
\end{tabular}

Aspek yang terakhir yaitu aspek pertanggungjawaban. aspek pertangungjawaban ini merupakan pertanggungjawaban realisasi pelaksanaan APB nagari yang terdiri dari pendapatan, belanja, dan pembiayaan yang disampaikan oleh Wali Nagari kepada Bupati setiap akhir tahun anggaran. Aspek pertanggujawaban di Kecamatan Koto XI Tarusan ini mencapai 68\%. Hal ini berarti bahwa lebih dari setengah nagari di Kecamatan ini telah sesuai dengan peraturan. Butir yang paling sedikit dilaksanakan oleh nagari adalah butir mengenai kewajiban Wali Nagari dalam menyampaiakan laporan pertanggungjawaban kepada Bupati. Hanya 6 nagari dari 23 nagari yang melaksanakan ini, selebihnya disebabkan karena yang menyempaiakan laporan tersebut bukanlah Wali Nagari melainkan pernagkat nagari yang lain, yakni sebanyak 13 nagari dilakukan oleh Sekretaris Nagari, 2 nagari dilakukan oleh Bendahara Nagaridan 2 nagari lainnya dilakukan oleh PTPKN.

Berdasarkan kelima aspek yang telah dipaparkan di atas, maka tingkat akuntabilitas pengelolaan keuangan nagari di Kecamatan Koto XI Tarusan adalah sebagai berikut: 
Tabel 6. Akuntabilitas Pengelolaan Keuangan Nagari di Kecamatan Koto XI Tarusan

\begin{tabular}{clcccc}
\hline No & \multicolumn{1}{c}{ Nagari } & $\begin{array}{c}\text { Jumlah Jawaban } \\
\text { Kuesioner "Ya" }\end{array}$ & $\begin{array}{c}\text { Jumlah Total } \\
\text { Kuesioner }\end{array}$ & $\begin{array}{c}\text { \% } \\
\text { akuntabilitas }\end{array}$ & Keterangan \\
\hline 1 & Siguntur & 11 & 25 & 44 & Tidak \\
2 & Siguntur Tua & 18 & 25 & 72 & Akuntabel \\
3 & Kp. Baru Korong Nan Ampek & 14 & 25 & 56 & Akuntabel \\
4 & Taratak Sungai Lundang & 12 & 25 & 48 & Tidak \\
5 & Barung-Barung Balantai & 15 & 25 & 60 & Akuntabel \\
6 & Barung-Barung Balantai Selatan & 20 & 25 & 80 & Akuntabel \\
7 & Barung-Barung Balantai Timur & 17 & 25 & 68 & Akuntabel \\
8 & Barung-Barung Balantai Tengah & 18 & 25 & 72 & Akuntabel \\
9 & Duku Utara & 16 & 25 & 64 & Akuntabel \\
10 & Duku & 20 & 25 & 80 & Akuntabel \\
11 & Batu Hampa & 20 & 25 & 80 & Akuntabel \\
12 & Batu Hampar Selatan & 23 & 25 & 92 & Akuntabel \\
13 & Setara Nanggalo & 18 & 25 & 72 & Akuntabel \\
14 & Nanggalo & 13 & 25 & 80 & Akuntabel \\
15 & Jinang Kp. Pansur Ampang Pulai & 15 & 25 & 52 & Akuntabel \\
16 & Ampang Pulai & 17 & 25 & 68 & Akuntabel \\
17 & Pulau Karam Ampang Pulai & 17 & 25 & 68 & Akuntabel \\
18 & Cerocok Anau Ampang Pulai & 12 & 25 & 48 & Akuntabel \\
19 & Kapuah Utara & 18 & 25 & 72 & Tidak \\
20 & Kapuh & 17 & 25 & 68 & Akuntabel \\
21 & Mandeh & 13 & 25 & 52 & Akuntabel \\
22 & Sungai Nyalo Mudiak Aia & 13 & & & Akuntabel \\
23 & Sungai Pinang & & & & \\
\hline
\end{tabular}

Berdasarkan tabel di atas, dapat dilihat bahwa 3 nagari di Kecamatan Koto XI Tarusan yang tidak akuntabel. Tingkat akuntabilitas ini dinilai berdasarkan kuesioner yang dilaksanakan kepada masing-masing perangkat nagari yang mengetahui tentang pengelolaan keuangan nagari di nagarinya. Butir pertanyaan di dalam kuesioner tersebut disesuaikan dengan Permendagri nomor 113 tahun 2014. Total nilai yang didapatkan dari kuesioner akan dipersentasekan, dan jika hasil persentase nya $>50 \%$ maka pengelolaan keuangan nagari di nagari tersebut dikatakan "akuntabel", namun jika persentase $<50 \%$ maka pengelolaanya dikatakan "tidak akuntabel". Berdasarkan hasil wawancara dengan informan kunci maka dapat dilihat bahwa ada 13\% nagari yang tidak sesuai dengan Permendagri nomor 113 tahun 2014 tentang pengelolaan keuangan nagari dan $87 \%$ nagari telah sesuai dengan Permendagri tersebut. Nagari yang tidak akuntabel tersebut dikarenakan masalah internal nagari, yakni seringnya pertukaran (reshuffle) perangkat nagari sehingga terjadinya kekosongan jabatan untuk sementara waktu. Hal ini menyebabkan kelancaran sistem dan kinerja di nagari tersebut menjadi terganggu sampai adanya pengganti dari perangkat nagari yang kosong tersebut. Hal ini seperti yang terjadi di nagari Kapuh Utara. Alasan dari pergantian perangkat nagari ada yang disebabkan karena perangkat nagari bersangkutan mengundurkan diri karena lebih memilihi profesinya selain perangkat nagari, ataupun berhenti karena masa jabatanya habis. Sedangkan dua nagari lainnya yakni nagari Taratak Sungai Lundang dan nagari Siguntur, berdasarkan hasil wawancara dengan informan tidak adanya masalah internal seperti yang dialami di nagari Kapuh Utara. Namun pengelolaan keuangan nagari dikedua nagari ini bersifat tidak akuntabel berkaitan dengan kompetensi perangkat nagari itu sendiri. Kompetensi ini bisa ditingkatkan dengan adanya pelatihan dan sosialisasi serta pengalaman dalam melaksanakan tugas. 


\section{KESIMPULAN}

Berdasarkan uraian pada hasil penelitian dan pembahasan mengenai akuntabilitas pengelolaan keuangan nagari di Kecamatan Koto XI Tarusan maka dapat diambil kesimpulan bahwa akuntabilitas dalam aspek perencanaan adalah 48\%, askuntabilitas dalam aspek pelaksanaan adalah $87 \%$, akuntabilitas dalam aspek penatusahan adalah $33 \%$, akuntabilitas dalam aspek pelaporan adalah 59\%, dan akuntabilitas dalam aspek pertanggungjawaban adalah $68 \%$. Berdasarkan hasil akhir dari kelima aspek tersebut terdapat 3 nagari dari 23 nagari di Kecamatan Koto XI Tarusan yang akuntabilitas pengelolaan keuangan nagarinya tidak akuntabel. Hal ini berarti bahwa ada 13\% nagari yang tidak sesuai dengan Permendagri nomor 113 tahun 2014 tentang Pengelolaan Keuangan Desa dan 87\% nagari telah sesuai dengan Permendagri tersebut. Persentase tertinggi adalah Nagari Batu Hampar Selatan yakni sebesar 92\% dan nagari yang terendah adalah Nagari Siguntur, Taratak Sungai Lundang, dan Kapuh Utara yakni sebesar $44 \%$. Nagari yang tidak akuntabel tersebut dikarenakan masalah internal nagari, yakni seringnya pertukaran (reshuffle) perangkat nagari sehingga terjadinya kekosongan jabatan untuk sementara waktu. Hal ini menyebabkan kelancaran sistem dan kinerja di nagari tersebut menjadi terganggu sampai adanya pengganti dari perangkat nagari yang kosong tersebut. Selain itu, kompetensi perangkat nagari juga mempengaruhi tingkat akuntabilitas pengelolaan keuangan nagari. Kompetensi ini bisa ditingkatkan dengan adanya pelatihan dan sosialisasi serta pengalaman dalam melaksanakan tugas.

\section{DAFTAR PUSTAKA}

[BPKD] Badan Pengelolaan Keuangan Daerah Kabupaten Pesisir Selatan.

[BPS] Badan Pusat Statistik. 2017. Kecamatan Koto IX Tarusan dalam Angka 2017. BPS Kabupaten Pesisir Selatan.

Haryanto, Sahmudin. 2007. Akuntansi Sektor Publik. Edisi PErtama. Universitas Diponegoro: Semarang.

Nafidah, Lina Nasehatun.2017.Akuntabilitas Pengelolaan Keuangan Desa di Kabupaten Jombang. [Jurnal]. Jakarta: Universitas Islam Negeri Jakarta.

Peraturan Pemerintah No 47 Tahun 2015

Peraturan Menteri Dalam Negeri no 113 Tahun 2014 tentang Pedoman Pengelolaan Keuangan Desa Undang - undang Nomor 6 Tahun 2014 tentang Desa. 